\title{
Fostering enthusiasm for research: Insights of undergraduate nursing students
}

\author{
Katherine Denae Warkentin ${ }^{1,2}$, Kristine Popik ${ }^{2}$, Rachel Usick ${ }^{2}$, Trevor Farley ${ }^{2}$ \\ 1. St. Boniface Hospital, Winnipeg, Canada. 2. Manitoba Centre for Nursing and Health Research, Faculty of Nursing, \\ University of Manitoba, Winnipeg, Canada.
}

Correspondence: Katherine Denae Warkentin. Address: Manitoba Centre for Nursing and Health Research, Helen Glass Centre for Nursing, 89 Curry Place, University of Manitoba, Winnipeg, Canada. Email: denae.warkentin@gmail.com

Received: November 29, 2013

Accepted: January 21, $2014 \quad$ Online Published: March 3, 2014

DOI : $10.5430 /$ jnep.v4n5p23

URL: http://dx.doi.org/10.5430/jnep.v4n5p23

\begin{abstract}
Engaging undergraduate nursing students in research is essential to promoting evidence-informed nursing, but can prove challenging. The purpose of this article is to highlight key experiences of four undergraduate nursing students who are enthusiastic about research with the potential to inform the education and training of undergraduate nursing students in research. Analysis of our own experiences emphasized that enthusiasm for research is promoted by the following factors: love of learning, opportunities for collaboration, support, confidence, overcoming research related challenges, research visibility and realizing the impact of research. Research related challenges and the invisibility of research served to diminish our enthusiasm. From these observations, we concluded that to promote nursing student enthusiasm for research, opportunities for exposure to research need to be available, allowing students to grasp the nature and impact of nursing research. More studies are needed to assess the research experiences of undergraduate nursing students.
\end{abstract}

\section{Key words}

Undergraduate students, Nursing, Education, Research

\section{I ntroduction}

Evidence-informed nursing is an ongoing process that integrates research evidence, clinical expertise, client preferences and other resources to plan and implement care in health care settings ${ }^{[1]}$. This process is foundational to the nursing profession and consequently to nursing education. To understand and achieve evidence-informed nursing, research capacity is required ${ }^{[2]}$. Educational institutions and educators have a responsibility to support nursing students in acquiring competencies to enable them to provide evidence-informed nursing and to "promote a spirit of inquiry, critical thinking, openness to change and a philosophy of life-long learning” (p. 2) ${ }^{[1]}$. Engaging undergraduate nursing students in research, however, can be challenging. The limited literature on nursing students' attitudes towards research has revealed mixed results. The purpose of this article is to highlight key experiences of four undergraduate nursing students who are enthusiastic about research with the potential to inform the education and training of undergraduate nursing students in research. 


\section{Background}

The literature examining undergraduate nursing students' perceptions of research is limited and what is available depicts somewhat mixed results. Halcomb and Peters ${ }^{[3]}$ identified that nursing students often perceive research as difficult and confusing, which may contribute to the distress, anxiety and negative attitudes students often develop in relation to research. Kennel, Burns, and Horn ${ }^{[4]}$ noted that anecdotally, nursing students regard engaging in research projects as unrealistic given their other responsibilities within educational programs and view research projects as intimidating. In a qualitative study examining nursing students' perceptions of research, Ax and Kincade ${ }^{[5]}$ found that students were uncertain about the usefulness of research in practice. Uncertainty was often linked to a lack of understanding of the research process or struggling to recall research terminology and skills. Several students had interesting ideas for future research, but had little motivation to follow through with them. Students emphasized this lack of motivation emanated from not expecting to study research, and having a poor understanding of the nature and usefulness of nursing research ${ }^{[5]}$. However, more positive perceptions of research were evident in the findings of a study carried out by Bjorkstrom, Johnasson, Hamrin, and Athlin ${ }^{[6]}$. These researchers used a questionnaire to assess Swedish nursing students' attitudes toward research and found that most of the nursing students in their study viewed research positively with $60 \%$ expecting to use research in their daily work ${ }^{[6]}$.

It has been argued that student-research connections are often ignored, with lack of student exposure and involvement in research, especially in the early years of undergraduate education ${ }^{[7]}$. Some authors have gone further and suggested that research is invisible to students in university settings. Zamorski ${ }^{[8]}$ reported that students valued being close to research and the idea of being a part of a university research community, but felt excluded from research activities due to a lack of understanding and lack of access to the research being conducted. Zamorski ${ }^{[8]}$ discovered that lecturers also saw research as invisible to students, commenting on research as a private activity where students were only rarely permitted to see more than the product. Robertson and Blackler ${ }^{[9]}$ noted that the relationship students have with research varies. In interviews with university students enrolled in physics, geography and English programs, Robertson and Blackler ${ }^{[9]}$ found some were frustrated with the extent to which research was hidden from them and that students valued an awareness of the research community. Robertson and Blackler ${ }^{[9]}$ suggest that this frustration may be caused by delayed student participation in the research community and students not understanding their relationship to this community. Students' lack of understanding of their relationship to the research community was linked to an incomplete vision of research and being unable to relate what they were learning to disciplinary research ${ }^{[9]}$.

Given undergraduate students' varying views of research and that higher education institutions are increasingly promoting undergraduate student exposure to research, discovering ways to inspire students to become involved in research is imperative ${ }^{[10]}$. Our own research experiences as undergraduate nursing students will be discussed in this article in order to contribute to this limited body of knowledge and the implications for education and training of undergraduate nursing students in research will be highlighted.

\section{Our research experiences}

The authors include four undergraduate nursing students at the University of Manitoba, Faculty of Nursing, all of whom were employed through the Manitoba Centre for Nursing and Health Research (MCNHR) as 2012 summer research interns. The research centre summer internship program actively engages undergraduate nursing students by providing summer employment opportunities that involve one-on-one collaboration and mentoring by nursing faculty members in one or more of their research projects. Depending on the research project, students were expected to participate in various ways. For example, student involvement included recruiting study participants, performing literature searches, assisting with ethics proposals, and analyzing transcripts. Each of the interns submitted a narrative of approximately two pages describing their experiences with research as research interns and nursing students. These experiences could include any involvement or perceptions relating to research, such as personal experiences working with nurse researchers or course- 
work in the undergraduate program. To guide the narrative process, we were asked to include experiences that generated, maintained or diminished our enthusiasm for research. We then individually reviewed each of the narratives, including our own narrative, and met to discuss both common and unique experiences. A faculty member also reviewed the narratives and met with us at a subsequent meeting to discuss our experiences.

\section{Research experience highlights}

\section{Factors that generated or maintained passion for research}

In reviewing the narrative accounts of our research related experiences, several common factors were identified that helped generate and maintain our passion for research or diminish it. No formal method of analysis was implemented and factors were simply analyzed through identification of common experiences and discussion as to whether these experiences served to generate and maintain our research passion or diminish it and why. One factor that contributed to our passion for research was an underlying love of learning. For example, one co-author stated that she was attracted to nursing because it was a career that provided the opportunity to be a life-long learner. This love of learning and desire to be a life-long learner was seen as an intrinsic component to our motivation for becoming involved in research. Nursing research and consequently nursing knowledge are constantly advancing. As nursing students, research involvement allowed us the opportunity to understand what types of questions nurse researchers were asking and why they were asking them. We were then able to apply this same method of curiosity to how we view nursing research and practice, allowing us to see how this love of learning could be used to advance nursing knowledge through research.

Collaboration and support were other factors viewed by all students as necessary to generate and maintain our enthusiasm for research. Collaboration was defined as working together with others towards a mutually beneficial goal. We appreciated the opportunity to work closely alongside nurse researchers, research centre staff and other research interns on various projects. Collaboration was also described as contributing to feeling involved and valued in the work of our research mentors. One student commented, "They (the researchers) truly respected my opinion and allowed me to have an active part in their research process.” Alternatively, support was defined as receiving assistance that benefited the student, and consequently the research study, but was just as essential as collaboration to our success and interest in research. Some examples of support included research software training sessions, access to a research technician, nursing librarians, and administrative staff. Opportunities for collaboration and support, as well as gaining practical skills served to increase student confidence. Increased confidence with utilizing and conducting research resulted in students realizing their potential as researchers and subsequently their ability to pursue graduate and doctoral studies.

In addition, through participating in the research process students began to grasp the impact of this work, which contributed to their enthusiasm for research. As one student specified, "Another factor that has fostered my passion for research is when you get to see the difference it makes." Given that we all contributed to various research projects, everyone agreed that seeing for ourselves the potential impact research had on the health and well-being of people reinforced the relationship between research findings and nursing practice. Recognizing the impact of research also involved realizing the volume of knowledge yet to be discovered. Gaps in current knowledge acted as incentives to explore these un-researched areas. As one student noted, hearing a professor say, "I don’t know” was motivation to examine and implement research.

\section{Factors that diminished passion for research}

The multiple realities of becoming involved in research were an aspect of our experiences that diminished as well as generated and maintained our enthusiasm. These realities were defined as students viewing the actuality of multiple dimensions of the research process. These dimensions ranged from applying for ethics approval and funding to analyzing complex data and often related to acknowledging the time and energy that it takes to conduct research. Delays and tedious 
tasks often caused students to become frustrated. Yet, the logistics of nursing research also contributed to our enthusiasm for research by stimulating us to think critically throughout the research process and overcome these challenges.

Another aspect that diminished our enthusiasm was the perceived invisibility of research prior to our experiences as research interns. As one student commented, "Now I realize that there are amazing researchers here (within the University of Manitoba, Faculty of Nursing) who are generating a wealth of knowledge and advancements in patient care. I call it my inside look at the faculty." It was through exposure to the research being conducted within our own nursing faculty that we began to see what one student referred to as "a whole new world of research." Another student stated, "I feel extremely fortunate that I have been exposed to this whole other side of nursing." Making this new world visible contributed to our enthusiasm for research and helped us to see what nursing research is and why it is important.

\section{I mplications for undergraduate nursing educators}

As evidenced by our own experiences, for students to feel optimistic about research, it is crucial that aspects serving to generate and maintain a student's enthusiasm for research must outweigh those acting to diminish it. As research interns we were given the opportunity to experience an immense number of factors that generated and maintained our interest in research. The benefits of undergraduate students working collaboratively with faculty members on original research have been documented in the literature. Many of these benefits are similar to those we have reported ${ }^{[11,12]}$.

In our experience, the benefits of being involved in research as undergraduate students only surfaced as research became more visible. As nursing students, we were not aware of the research conducted by faculty members prior to our involvement with the research institute and now had an "inside look" at our faculty. The Boyer Commission on Educating Undergraduates in the Research University ${ }^{[13]}$ described research universities as fragmented ecosystems where research faculty and undergraduate students exist in disconnected communities where interaction with each other is not expected. From our own experiences, this fragmentation has consequences for students realizing the importance of conducting and disseminating research and using evidenced-based practice in nursing.

It is also our view that generating passion for research among undergraduate nursing students directly involved in research includes allowing them to see beyond the delays and tedious tasks that constitute some of the challenges associated with research. As student research assistants, nursing faculty research mentors worked closely with us to ensure we understood the relevance of the project to changing nursing practice and policy. Similar to our own experiences with the challenges of research, Vessey and DeMarco ${ }^{[14]}$ noted that when nursing students act as research assistants in a work-for-hire model, tasks could become routine and meaningless. In order to promote the possible impact of research, nursing students must be given opportunities to grasp the entire research venture ${ }^{[14]}$. From our own experiences, this connection to the larger scope of research and overcoming research related challenges is dependent on the commitment of research mentors and their willingness to discuss how students' tasks relate to the larger research trajectory.

We agree with the statement made by student researchers interviewed by Zamorski ${ }^{[8]}$ that explicit assistance and opportunities are needed for research to be visible in the university setting, also recognizing that not every undergraduate student has the opportunity to be directly involved in research. Lingler ${ }^{[15]}$ while reflecting on her own experience as a nursing student, focused on the lack of opportunities for nursing faculty to engage undergraduate students in their research as a possible reason for students' lack of awareness. The results from a survey of University of Alberta students, from 14 different faculties, supports Lingler's ${ }^{[15]}$ claim. Approximately 55\% had experienced both learning research methods and an instructor discussing research in class, but almost $20 \%$ of the students who responded did not report having any research experiences ${ }^{[10]}$. When given the opportunity to describe the role of research at their university, one theme was that research opportunities were not accessible by every student ${ }^{[10]}$. Zamorski ${ }^{[8]}$ suggests that it seems even when students actively search for ways to be involved in research they cannot always find or access them. We see this as a widespread 
issue that is especially relevant in nursing, as our experiences have enabled us to understand the importance of leading edge applied research to nursing practice, promotion, and appreciation of evidence-informed practice.

This reported lack of awareness and lack of opportunity for students to actively engage in research suggests that we must critically reflect on interventions that enable undergraduate students to be a part of an inclusive research community ${ }^{[10]}$. One example is faculty members explaining the relevance of research to course material discussed within their classes and participation in mentoring programs ${ }^{[16]}$. As nursing students, we also see value in the role of clinical nurse educators promoting evidence-informed practice, as this was often a key area where nursing research invisibility existed in our own experience. In addition, we observed that encouragement by peers promoted awareness and confidence to seek out and apply for available research opportunities. Finally, research intern programs such as those offered by our university serve to increase the visibility of nursing research.

\section{Conclusion}

Engaging nursing students in research is necessary for promoting evidence-informed practice, but can be challenging. As undergraduate nursing students, we noted factors which contributed to our enthusiasm for research: love of learning, opportunities for collaboration, support, confidence, overcoming challenges associated with research, research visibility and realizing the impact of research. Research related challenges and the invisibility of research served to diminish our enthusiasm. By sharing our own research experiences we hope to inform future education and training of undergraduate nursing students in research.

\section{Competing interests}

The authors declare that they have no competing interests.

\section{Acknowledgements}

The authors wish to thank Diane Cepanec, Associate Director, Manitoba Centre for Nursing and Health Research and Dr. Marie Edwards, RN, PhD, Associate Professor, University of Manitoba, Faculty of Nursing, for their support and guidance throughout the process of creating this manuscript. Without the two of you, we would not have had the opportunity or the inspiration to tell our story. Thanks are also due to Dr. Diana Clarke, RN, PhD, Associate Professor and Associate Dean, Research, University of Manitoba, Faculty of Nursing; Director, Manitoba Centre for Nursing and Health Research, for her support in the final steps of our manuscript submission.

\section{References}

[1] Canadian Nurses Association. Position statement: Evidence-informed decision-making and nursing practice. 2010. Available from: http://www2.cnaaiic.ca/CNA/documents/pdf/publications/PS113_Evidence_informed_2010_e.pdf

[2] Power-Kean K. Opening new doors. Canadian Nurse. 2010; 106(2): 28-31.

[3] Halcomb EJ, Peters K. Nursing student feedback on undergraduate research education: Implications for teaching and learning. Contemporary Nurse. 2009; 33(1): 59-68. http://dx.doi.org/10.5172/conu.33.1.59

[4] Kennel S, Burns S, Horn H. Stimulating student interest in nursing research: A program pairing students with practicing clinician researchers. Journal of Nursing Education. 2009; 48(4): 209-212. http://dx.doi.org/10.3928/01484834-20090401-06

[5] Ax S, Kincade E. Nursing students' perceptions of research: Usefulness, implementation and training. Journal of Advanced Nursing. 2001; 35(2): 161-170. http://dx.doi.org/10.1046/j.1365-2648.2001.01833.x

[6] Bjorkstrom ME, Johansson IS, Hamrin EKF, Athlin, EE. Swedish nursing students' attitudes to and awareness of research and development within nursing. Journal of Advanced Nursing. 2003; 41(4): 393-402. http://dx.doi.org/10.1046/j.1365-2648.2003.02557.x

[7] Brew A. Research and teaching: Beyond the divide. New York, NY: Palgrave Macmillan; 2006

[8] Zamorski B. Research-led teaching and learning in higher education: A case. Teaching in Higher Education. 2002; 7(4): 411-427. http://dx.doi.org/10.1080/135625102760553919

Published by Sciedu Press 
[9] Robertson J, Blackler G. Students' experiences of learning in a research environment. Higher Education Research \& Development. 2006; 25(3): 215-229. http://dx.doi.org/10.1080/07294360600792889

[10] Wuetherick B, McLaughlin L. Exploring students' perceptions of research in the learning environment: A partnership to enhance our understanding of the undergraduate student experience. In Staff-student partnerships in higher education. S. Little, ed. New York, NY: Continuing International Publishing Group, 2011, 185-200.

[11] Hunter A, Laursen SL, Seymour E. Becoming a scientist: The role of undergraduate research in students' cognitive, personal, and professional development. Science Education. 2006; 91: 36-74. http://dx.doi.org/10.1002/sce.20173

[12] Wheeler EC, Hardie T, Schell K, Plowfield L. Symbiosis-Undergraduate research mentoring and faculty scholarship in nursing. Nursing Outlook. 2008; 56(1): 9-15. http://dx.doi.org/10.1016/j.outlook.2007.09.001

[13] The Boyer Commission on Educating Undergraduates in the Research University. Reinventing undergraduate education: A blueprint for America's research universities. 2010. http://www.niu.edu/engagedlearning/research/pdfs/Boyer_Report.pdf

[14] Vessey JA, DeMarco RF. The undergraduate research fellows program: A unique model to promote engagement in research. Journal of Professional Nursing. 2008; 24(6): 358-363. http://dx.doi.org/10.1016/j.profnurs.2008.06.003

[15] Lingler JH. From whispering to roaring: Engaging undergraduate nursing students in research. Research in Gerontological Nursing. 2012; 5(3): 150-151. http://dx.doi.org/10.3928/19404921-20120605-06

[16] University of Alberta (2004). Final Report: Working group on teaching and research. Integrating research and teaching at the University of Alberta: Creating a foundation for an inquiry-based life. 2004. Available from:

http://www.uofaweb.ualberta.ca/researchandstudents/pdfs/finalreportworkinggroup.pdf 